\title{
Nested Case-Control Study of One-Carbon Metabolites in Mid-Pregnancy and Risks of Cleft Lip With and Without Cleft Palate
}

\author{
GARY M. SHAW, STEIN EMIL VOLLSET, SUZAN L. CARMICHAEL, WEI YANG, RICHARD H. FINNELL, HENK BLOM,
} AND PER M. UELAND

\begin{abstract}
Department of Pediatrics [G.M.S.], Stanford University School of Medicine, Palo Alto, CA, 94305; Medical Birth Register [S.E.V.], Norwegian Institute of Public Health, Bergen, N-5018, Norway; California Research Division [S.L.C., W.Y.], March of Dimes Foundation, Oakland, CA, 94609; Institute Biosciences Technology [R.H.F.], Texas A\&M Health Science Center, Houston, TX, 77030; Department of Clinical Chemistry [H.B.], VU University Medical Center, 1081 HV Amsterdam, The Netherlands; Department of Internal Medicine [P.M.U.], University of Bergen, Haukeland University Hospital N-5021 Bergen, Norway
\end{abstract}

\begin{abstract}
Evidence exists for an association between use of vitamin supplements with folic acid in early pregnancy and reduced risk for offspring with cleft lip with/without cleft palate (CLP). A few observations have been made about nutrients related to one-carbon metabolism other than folate. Our prospective study attempted to extend information on nutrition and CLP by measuring nutrient analytes in mid-pregnancy sera. This study included data from a repository of women's mid-pregnancy serum specimens collected in California from 2003-04. Each woman's specimen was linked with delivery information to determine whether her fetus had CLP or another structural malformation, or was nonmalformed. We identified 89 CLP cases. We randomly selected 409 specimens as controls. Specimens were tested for homocysteine, methylmalonic acid, folate, vitamin $\mathrm{B}_{12}$, pyridoxal phosphate, pyridoxal, pyridoxic acid, riboflavin, choline, betaine, methionine, methionine sulfoxide, cysteine, cystathionine, arginine, and asymmetric and symmetric dimethylarginine. We observed three analytes with odds ratios unlikely to be explained by random variation, i.e., elevated CLP risks were observed for low levels and for high levels of pyridoxal phosphate (vitamin $\mathrm{B}_{6}$ ), higher levels of choline, and low levels of symmetric dimethylarginine. These data did not show meaningful differences between cases and controls for any other analytes. (Pediatr Res 66: 501-506, 2009)
\end{abstract}

$\mathrm{E}^{\mathrm{v}}$ idence exists for an association between maternal use of a vitamin supplement with folic acid in early pregnancy and a reduced risk for offspring with cleft lip with/without cleft palate (CLP). This, evidence includes, i) epidemiologic studies that have shown reductions in both occurrence and recurrence (subsequent affected sibling) risks of CLP in infants whose mothers took vitamin supplements containing folic acid (1-11), ii) a reduction in prevalence of CLP following mandatory folic acid fortification in the US (12), iii) mothers' use of folic acid antagonist medications associated with an increased risk to deliver offspring with CLP (13), and

Received May 28, 2009; accepted July 13, 2009.

Correspondence: Gary M. Shaw, Ph.D., Stanford University, Medical School Office, Building x159, 251 Campus Drive, Stanford, CA 94305; e-mail: GMShaw@stanford.edu

Supported by funds from the Centers for Disease Control and Prevention, Center of Excellence Award U50/CCU913241.

The findings and conclusions in this report are those of the authors and do not necessarily represent the views of the California Department of Public Health. iv) biologic plausibility for a relation between folic acid and reduced risk for CLP from experimental studies (14).

Although folate has been the focus for many of the inquiries about periconceptional nutrition and clefting, there have been a few observations made about dietary intake or use of supplements involving nutrients related to one-carbon metabolism other than folate. We recently observed decreased risks of CLP associated with increasing intakes of total protein, alanine, choline, methionine, cysteine, iron and riboflavin (15). Investigators in the Netherlands have observed reduced risks of CLP associated with increased maternal dietary intakes of several B-vitamins, including thiamine, niacin, pyridoxine, and increased intakes of vegetable protein, fiber, beta-carotene, vitamin $\mathrm{C}$, vitamin $\mathrm{E}$, iron, and magnesium $(16,17)$. Recent observations from the Danish prospective study found evidence to indicate that use of $\mathrm{B}_{6}$ and $\mathrm{B}_{12}$ supplements reduced risks of CLP (18).

A few studies have specifically measured nutrients in serum among women who delivered infants with CLP (19-22). These studies found serum concentrations that were lower in zinc (20), vitamin $B_{6}(19,21,22)$, vitamin $B_{12}(21)$, and higher in folate (22). However, these studies relied on postpartum measurements rather than measurements in early pregnancy, i.e., closer to the relevant embryonic timing for the development of the lip and palate which is gestational weeks $5-10$. The current prospective study attempts to extend the knowledge base on nutrition and CLP by measuring numerous nutrient analytes in mid-pregnancy sera obtained from a sizable population in California.

\section{METHODS}

This study included data from a large and unique mid-pregnancy serum specimen bank of pregnancies in California. Specimens were collected from approximately $70 \%$ of women during the $15^{\text {th }}-18^{\text {th }}$ week of pregnancy. These sera were collected from women who resided in selected regions of California (Orange, San Diego, and Central Valley counties). Sera were collected from women as part of the California Expanded AFP (alpha-feto-protein) program that screens for neural tube defects and cytogenetic abnormalities. The collection and processing of specimens was as follows: 1) samples were taken at draw stations using BD ${ }^{\mathrm{TM}}$ Vacutainer $3.5 \mathrm{~mL}$ serum separator tubes with no anticoagulants or preservatives and centrifuged within $30 \mathrm{~min}$; 2) samples were received by designated clinical laboratories from draw stations at room

Abbreviations: AFP, alpha-feto-protein; CLP, cleft lip with/without cleft palate 
temperature, on average $3.0 \mathrm{~d}$ after draw; 3) AFP screening assays were run on samples usually on the day received; 4) samples were refrigerated up to $7 \mathrm{~d}$ if further testing was necessary; 5) samples were sent on cold packs via overnight mail to the serum storage bank; and 6) samples were aliquoted, labeled with barcodes, and frozen at $-80^{\circ} \mathrm{C}$ within an average of $3.5 \mathrm{~d}$ of receipt at the serum storage bank.

Each woman's serum specimen was linked with delivery outcome information to determine whether her fetus had CLP or any other structural malformation ascertained by the California Birth Defects Monitoring Program (23) or was born nonmalformed. The study included deliveries that were liveborn or stillborn (fetal deaths at greater than 20 wk gestation) in 20032004. There were approximately 111,077 births represented in both the serum bank and the California Birth Defects Monitoring Program. Among these births, we identified 105 deliveries that involved CLP (cases). Of the 105, we excluded 16 with diagnoses involving holoprosencephaly, limb/body/wall defect, trisomy 13 , or trisomy 18 owing to a suspected different underlying etiology. Of the 89 CLP cases available for further study, 80 were isolated, i.e., the phenotype did not involve any other major congenital abnormality. We also randomly selected 409 pregnancy specimens that were collected during the same time period and corresponded to nonmalformed infants at delivery (controls). Thus, this was a nested case-control study. All samples were obtained with approval from the California Health and Welfare Agency Committee for the Protection of Human Subjects.

Serum specimens for the 498 cases and controls were sent on cold packs to the University of Bergen for analyte measurements. The analytes measured were: total homocysteine, methylmalonic acid, folate, vitamin $\mathrm{B}_{12}$, pyridoxal phosphate, pyridoxal, pyridoxic acid, riboflavin, total choline, betaine, methionine, methionine sulfoxide, total cysteine, cystathionine, asymmetric dimethylarginine, symmetric dimethylarginine, and creatinine. To assess cigarette smoking exposures, the metabolite cotinine was measured. No smoke exposure was defined as values $<5 \mathrm{nmol} / \mathrm{L}$ and any smoke exposure was defined as $\geq 5 \mathrm{nmol} / \mathrm{L}$. Details about all laboratory assays except total choline can be found elsewhere (24). Total choline was measured after conversion of choline esters to free choline in the presence of phospholipase D. A serum sample of $45 \mu \mathrm{L}$ was mixed with $18 \mu \mathrm{L}$ solution containing phospholipase D (Sigma Chemical Co., $2.8 \mathrm{U} / \mu \mathrm{L}), \mathrm{CaCl} 2(86 \mathrm{mM})$, and Triton $(0.44 \%)$. Then, $30 \mu \mathrm{L}$ dithioerythritol $(147 \mathrm{mM})$ and $60 \mu \mathrm{L}$ TCA containing $400 \mu \mathrm{M}$ d7Choline were added to the incubation mixture. After centrifugation, the supernatant was analyzed by LC-MS/MS using a method optimized for the determination of free choline (24). Laboratory analyses were performed blind to case and control status.

We compared mean levels of analytes between cases and controls with $t$ tests. We also estimated risks using odds ratios and $95 \%$ confidence intervals (SAS 9.1). Models were constructed to assess effects associated with categories of the measured analytes. Specifically, we categorized measures as $<25$ th percentile, 25th-74th percentile, and $\geq 75$ th percentile based on the distribution of each analyte among controls. The 25th-74th percentile was used as the reference group. We analyzed data for linear (logistic regression) and nonlinear (spline regression) effects and found no evidence for the latter. Available from intake forms associated with the screening program were the demographic factors maternal race/ethnicity (Hispanic; white, non Hispanic; Asian; Black; other) and maternal age $(<25 ; 25-29 ; 30-34$; and $>34$ y). These factors along with cigarette smoke exposure defined by cotinine levels were considered as covariates in some analyses.

\section{RESULTS}

Table 1 shows similar racial/ethnic and age distributions between cases and controls. Table 2 shows means and standard deviations of each measured analyte. We observed statistically significantly $(p \leq 0.05)$ lower mean levels in cases than in controls for vitamin $\mathrm{B}_{12}$, betaine, methionine sulfoxide, total cysteine, and symmetric dimethylarginine. Higher mean levels of choline were observed among cases than controls. Removing 11 cases and 32 controls considered exposed to cigarette smoke based on cotinine levels did not substantially alter these findings (not shown).

Given that comparisons of mean analyte values may not adequately reveal effects that could be associated with values toward the tails of the distribution, we explored lower and upper quartiles (cutpoints defined by the control distribution). As shown in Table 3, relative to the $25^{\text {th }}-74^{\text {th }}$ percentile, we
Table 1. Characteristics of cleft lip/palate-affected and unaffected (nonmalformed controls) deliveries, California 2003-2005

\begin{tabular}{lcc}
\hline & $\begin{array}{c}\text { Cleft lip/palate cases } \\
(n=89) \\
n(\%)\end{array}$ & $\begin{array}{c}\text { Controls } \\
(n=409) \\
n(\%)\end{array}$ \\
\hline Race/ethnicity & & \\
Hispanic & $40(44.9)$ & $196(47.9)$ \\
White non-Hispanic & $31(34.8)$ & $143(35.0)$ \\
Asian & $7(7.9)$ & $37(9.1)$ \\
Black & $2(2.3)$ & $12(2.9)$ \\
Other & $9(10.1)$ & $20(4.9)$ \\
Age (y) & & \\
$<25$ & $29(32.6)$ & $132(32.3)$ \\
$25-29$ & $26(29.2)$ & $91(22.3)$ \\
$30-34$ & $24(27.0)$ & $137(33.5)$ \\
$\geq 34$ & $10(11.2)$ & $49(12.0)$ \\
\hline
\end{tabular}

* Percentages may not equal 100 owing to missing data or rounding.

Table 2. Mean values of selected biochemical measures in midpregnancy serum specimens among deliveries with cleft lip/palate and deliveries without malformations, California 2003-2005

\begin{tabular}{|c|c|c|c|c|c|}
\hline \multirow[b]{2}{*}{ Serum measurements } & \multicolumn{2}{|c|}{$\begin{array}{l}\text { Cleft lip/palate } \\
\text { cases }(n=89)\end{array}$} & \multicolumn{2}{|c|}{$\begin{array}{l}\text { Controls } \\
(n=409)\end{array}$} & \multirow[b]{2}{*}{$p$} \\
\hline & Mean & SD & Mean & SD & \\
\hline $\begin{array}{l}\text { Homocysteine (tHcy) } \\
(\mu \mathrm{mol} / \mathrm{L})\end{array}$ & 6.70 & 2.90 & 6.96 & 3.75 & 0.47 \\
\hline $\begin{array}{l}\text { Methylmalonic acid } \\
\qquad(\mu \mathrm{mol} / \mathrm{L})\end{array}$ & 0.16 & 0.09 & 0.15 & 0.05 & 0.28 \\
\hline Folate $(\mathrm{nmol} / \mathrm{L})$ & 38.18 & 21.87 & 36.48 & 20.88 & 0.49 \\
\hline Vitamin $B_{12}(\mathrm{pmol} / \mathrm{L})$ & 292.11 & 101.12 & 323.47 & 165.23 & 0.02 \\
\hline $\begin{array}{l}\text { Pyridoxal phosphate } \\
(\mathrm{nmol} / \mathrm{L})\end{array}$ & 67.41 & 52.39 & 72.19 & 63.17 & 0.45 \\
\hline Pyridoxal (nmol/L) & 60.74 & 83.26 & 63.19 & 143.87 & 0.83 \\
\hline Pyridoxic acid (nmol/L) & 61.56 & 88.26 & 64.47 & 153.27 & 0.81 \\
\hline Riboflavin (nmol/L) & 35.58 & 26.17 & 39.88 & 29.86 & 0.21 \\
\hline Total choline $(\mathrm{mmol} / \mathrm{L})$ & 3.09 & 0.46 & 2.98 & 0.41 & 0.02 \\
\hline Betaine $(\mu \mathrm{mol} / \mathrm{L})$ & 15.82 & 3.66 & 16.69 & 4.64 & 0.05 \\
\hline Methionine $(\mu \mathrm{mol} / \mathrm{L})$ & 36.92 & 10.58 & 36.28 & 9.72 & 0.58 \\
\hline $\begin{array}{l}\text { Methionine sulfoxide } \\
(\mu \mathrm{mol} / \mathrm{L})\end{array}$ & 1.68 & 0.73 & 1.99 & 1.37 & 0.003 \\
\hline $\begin{array}{l}\text { Total cysteine (tCys) } \\
(\mu \mathrm{mol} / \mathrm{L})\end{array}$ & 224.48 & 31.50 & 234.31 & 46.34 & 0.02 \\
\hline Cystathione $(\mu \mathrm{mol} / \mathrm{L})$ & 0.13 & 0.07 & 0.12 & 0.05 & 0.07 \\
\hline Arginine $(\mu \mathrm{mol} / \mathrm{L})$ & 159.67 & 41.24 & 151.22 & 50.85 & 0.10 \\
\hline $\begin{array}{l}\text { Asymmetric dimethylarginine } \\
(\mu \mathrm{mol} / \mathrm{L})\end{array}$ & 0.54 & 0.14 & 0.55 & 0.16 & 0.51 \\
\hline $\begin{array}{l}\text { Symmetric dimethylarginine } \\
(\mu \mathrm{mol} / \mathrm{L})\end{array}$ & 0.37 & 0.08 & 0.42 & 0.10 & 0.0001 \\
\hline Creatinine $(\mu \mathrm{mol} / \mathrm{L})$ & 49.16 & 11.34 & 49.61 & 8.44 & 0.72 \\
\hline
\end{tabular}

observed three analytes (pyridoxal phosphate, choline, and symmetric dimethylarginine) that had associated odds ratios unlikely to be explained by random variation. For pyridoxal phosphate, elevated CLP risks were observed for low levels and for high levels. For choline, increased CLP risks were observed for higher levels. For symmetric dimethylarginine, increased CLP risks for low levels and decreased risks for high levels were observed. The risk pattern observed with choline and symmetric dimethylarginine each had statistically significant trend effects (Table 3). Adjustment of these analyses by maternal age and race/ethnicity (as well as folate, not shown) did not produce results that differed substantially from their 
Table 3. Effect estimates (odds ratios) for pregnancies affected with cleft lip/palate and selected biochemical measures in mid-pregnancy serum specimens

\begin{tabular}{|c|c|c|c|c|c|c|}
\hline Percentile measure* & $\begin{array}{l}\text { No. cases } \\
(n=89)\end{array}$ & $\begin{array}{l}\text { No. controls } \\
(n=409)\end{array}$ & Odds ratio & $95 \% \mathrm{CI}$ & $\begin{array}{c}\text { Adjusted } \\
\text { odds ratio** }\end{array}$ & $95 \% \mathrm{CI}$ \\
\hline \multicolumn{7}{|l|}{ Total homocysteine } \\
\hline$<4.90$ & 22 & 101 & 1.1 & $0.6-2.0$ & 1.1 & $0.6-2.0$ \\
\hline $4.90-7.14$ & 40 & 205 & Ref & & Ref & \\
\hline$\geq 7.15$ & 27 & 103 & 1.3 & $0.8-2.3$ & 1.4 & $0.8-2.4$ \\
\hline$p$ for trend & & & 0.54 & & 0.48 & \\
\hline \multicolumn{7}{|l|}{ Methylmalonic acid } \\
\hline$<0.12$ & 17 & 98 & 0.7 & $0.4-1.3$ & 0.7 & $0.4-1.3$ \\
\hline $0.12-0.16$ & 50 & 206 & Ref & & Ref & \\
\hline$\geq 0.17$ & 22 & 105 & 0.9 & $0.5-1.5$ & 0.9 & $0.5-1.5$ \\
\hline$p$ for trend & & & 0.63 & & 0.57 & \\
\hline \multicolumn{7}{|l|}{ Folate, serum } \\
\hline$<23.32$ & 16 & 102 & 0.6 & $0.3-1.1$ & 0.6 & $0.3-1.1$ \\
\hline $23.32-43.60$ & 52 & 204 & Ref & & Ref & \\
\hline$\geq 43.61$ & 21 & 103 & 0.8 & $0.5-1.4$ & 0.8 & $0.5-1.4$ \\
\hline$p$ for trend & & & 0.51 & & 0.47 & \\
\hline \multicolumn{7}{|l|}{ Vitamin $\mathrm{B}_{12}$} \\
\hline$<223.80$ & 25 & 101 & 1.0 & $0.6-1.8$ & 1.1 & $0.6-1.8$ \\
\hline $223.80-381.39$ & 48 & 203 & Ref & & Ref & \\
\hline$\geq 381.40$ & 16 & 102 & 0.7 & $0.4-1.2$ & 0.7 & $0.4-1.3$ \\
\hline$p$ for trend & & & 0.21 & & 0.23 & \\
\hline \multicolumn{7}{|l|}{ Pyridoxal phosphate } \\
\hline$<35.25$ & 29 & 102 & 1.8 & $1.0-3.1$ & 1.8 & $1.0-3.1$ \\
\hline $35.25-79.88$ & 33 & 204 & Ref & & Ref & \\
\hline$\geq 79.89$ & 27 & 103 & 1.6 & $0.9-2.8$ & 1.6 & $0.9-2.9$ \\
\hline$p$ for trend & & & 0.77 & & 0.72 & \\
\hline \multicolumn{7}{|l|}{ Pyridoxal } \\
\hline$<18.51$ & 18 & 102 & 0.8 & $0.4-1.4$ & 0.8 & $0.4-1.4$ \\
\hline $18.51-51.96$ & 48 & 204 & Ref & & Ref & \\
\hline$\geq 51.97$ & 23 & 103 & 0.9 & $0.5-1.6$ & 0.9 & $0.5-1.7$ \\
\hline$p$ for trend & & & 0.51 & & 0.53 & \\
\hline \multicolumn{7}{|l|}{ Pyridoxic acid } \\
\hline$<15.70$ & 15 & 102 & 0.6 & $0.3-1.1$ & 0.6 & $0.3-1.1$ \\
\hline $15.70-62.40$ & 52 & 204 & Ref & & Ref & \\
\hline$\geq 62.41$ & 22 & 103 & 0.8 & $0.5-1.5$ & 0.8 & $0.5-1.4$ \\
\hline$p$ for trend & & & 0.35 & & 0.36 & \\
\hline \multicolumn{7}{|l|}{ Riboflavin } \\
\hline$<22.34$ & 28 & 102 & 1.2 & $0.7-2.1$ & 1.2 & $0.7-2.1$ \\
\hline $22.34-46.65$ & 45 & 204 & Ref & & Ref & \\
\hline$\geq 46.66$ & 16 & 103 & 0.7 & $0.4-1.3$ & 0.7 & $0.4-1.3$ \\
\hline$p$ for trend & & & 0.10 & & 0.09 & \\
\hline \multicolumn{7}{|l|}{ Choline, total } \\
\hline$<2.71$ & 17 & 100 & 1.0 & $0.5-1.8$ & 1.0 & $0.5-1.8$ \\
\hline $2.71-3.20$ & 36 & 206 & Ref & & Ref & \\
\hline$\geq 3.21$ & 36 & 102 & 2.0 & $1.2-3.4$ & 2.1 & $1.2-3.5$ \\
\hline$p$ for trend & & & 0.01 & & 0.01 & \\
\hline \multicolumn{7}{|l|}{ Betaine } \\
\hline$<13.55$ & 26 & 99 & 1.1 & $0.7-1.9$ & 1.2 & $0.7-2.0$ \\
\hline $13.55-18.79$ & 48 & 206 & Ref & & Ref & \\
\hline$\geq 18.80$ & 15 & 104 & 0.6 & $0.3-1.2$ & 0.6 & $0.3-1.2$ \\
\hline$p$ for trend & & & 0.10 & & 0.09 & \\
\hline \multicolumn{7}{|l|}{ Methionine } \\
\hline$<29.41$ & 20 & 102 & 0.8 & $0.5-1.5$ & 0.9 & $0.5-1.5$ \\
\hline $29.41-41.32$ & 48 & 204 & Ref & & Ref & \\
\hline$\geq 41.33$ & 21 & 103 & 0.9 & $0.5-1.5$ & 0.9 & $0.5-1.6$ \\
\hline$p$ for trend & & & 0.91 & & 0.92 & \\
\hline \multicolumn{7}{|l|}{ Methionine sulfoxide } \\
\hline$<1.15$ & 20 & 101 & 0.8 & $0.4-1.4$ & 0.8 & $0.4-1.3$ \\
\hline $1.15-2.31$ & 53 & 205 & Ref & & Ref & \\
\hline$\geq 2.32$ & 16 & 103 & 0.6 & $0.3-1.1$ & 0.6 & $0.3-1.1$ \\
\hline$p$ for trend & & & 0.54 & & 0.54 & \\
\hline \multicolumn{7}{|l|}{ Total cysteine } \\
\hline$<207.50$ & 24 & 102 & 1.0 & $0.6-1.7$ & 0.9 & $0.5-1.6$ \\
\hline $207.50-245.59$ & 50 & 204 & Ref & & Ref & \\
\hline$\geq 245.60$ & 15 & 103 & 0.6 & $0.3-1.1$ & 0.6 & $0.3-1.1$ \\
\hline$p$ for trend & & & 0.21 & & 0.24 & \\
\hline
\end{tabular}


Table 3. (Continued)

\begin{tabular}{|c|c|c|c|c|c|c|}
\hline Percentile measure* & No. Cases $(\mathrm{n}=89)$ & No. Controls $(\mathrm{n}=409)$ & Odds Ratio & $95 \% \mathrm{CI}$ & Adjusted Odds Ratio** & $95 \% \mathrm{CI}$ \\
\hline \multicolumn{7}{|l|}{ Cystathione } \\
\hline$<0.08$ & 11 & 85 & 0.6 & $0.3-1.2$ & 0.6 & $0.3-1.1$ \\
\hline $0.08-0.12$ & 47 & 209 & Ref & & Ref & \\
\hline$\geq 0.13$ & 31 & 115 & 1.2 & $0.7-2.0$ & 1.2 & $0.7-2.0$ \\
\hline$p$ for trend & & & 0.06 & & 0.06 & \\
\hline \multicolumn{7}{|l|}{ Arginine } \\
\hline$<125.37$ & 16 & 102 & 0.6 & $0.3-1.1$ & 0.6 & $0.3-1.1$ \\
\hline $125.37-183.68$ & 52 & 202 & Ref & & Ref & \\
\hline$\geq 183.69$ & 21 & 105 & 0.8 & $0.4-1.4$ & 0.8 & $0.5-1.4$ \\
\hline$p$ for trend & & & 0.55 & & 0.48 & \\
\hline \multicolumn{7}{|c|}{ Asymmetric dimethylarginine } \\
\hline$<0.45$ & 17 & 94 & 0.8 & $0.4-1.4$ & 0.8 & $0.4-1.5$ \\
\hline $0.45-0.60$ & 49 & 211 & Ref & & Ref & \\
\hline$>0.61$ & 23 & 104 & 1.0 & $0.6-1.6$ & 1.0 & $0.5-1.7$ \\
\hline$p$ for trend & & & 0.59 & & 0.63 & \\
\hline \multicolumn{7}{|c|}{ Symmetric dimethylarginine } \\
\hline$<0.34$ & 33 & 92 & 1.6 & $1.0-2.7$ & 1.6 & $0.9-2.6$ \\
\hline $0.34-0.47$ & 48 & 214 & Ref & & Ref & \\
\hline$\geq 0.48$ & 8 & 103 & 0.3 & $0.2-0.8$ & 0.3 & $0.2-0.7$ \\
\hline$p$ for trend & & & 0.0002 & & 0.0002 & \\
\hline \multicolumn{7}{|c|}{ Asymmetric dimethylarginine/arginine* 1000} \\
\hline$<2.62$ & 16 & 102 & 0.5 & $0.3-1.0$ & 0.6 & $0.3-1.0$ \\
\hline $2.62-4.47$ & 60 & 204 & Ref & & Ref & \\
\hline$\geq 4.48$ & 13 & 103 & 0.4 & $0.2-0.8$ & 0.4 & $0.2-0.8$ \\
\hline$p$ for trend & & & 0.65 & & 0.57 & \\
\hline \multicolumn{7}{|c|}{ Symmetric dimethylarginine/arginine* 1000} \\
\hline$<2.06$ & 32 & 102 & 1.3 & $0.8-2.1$ & 1.3 & $0.8-2.1$ \\
\hline $2.06-3.53$ & 51 & 204 & Ref & & Ref & \\
\hline$\geq 3.54$ & 6 & 103 & 0.2 & $0.1-0.6$ & 0.2 & $0.1-0.6$ \\
\hline$p$ for trend & & & 0.0004 & & 0.0003 & \\
\hline
\end{tabular}

* Categories were constructed corresponding to $<25,25-74$, and $\geq 75$ percentiles, based on distributions among control mothers.

** OR adjusted for maternal race/ethnicity and age.

unadjusted counterparts (Table 3). Analyses that excluded women with cigarette smoking exposure (11 case and 32 control women) also did not produce substantially different results.

We explored ratios of asymmetric dimethylarginine/ arginine and symmetric dimethylarginine/arginine. These analyses revealed a highly significant trend for the symmetric dimethylarginine/arginine ratio (Table 3 ) with increasing ratio values associated with decreased CLP risk. Higher ratio values of asymmetric dimethylarginine/arginine were also associated with decreased CLP risk.

We simultaneously investigated four B-vitamin-related analytes, i.e., pyridoxal phosphate, riboflavin, betaine, and vita$\min B_{12}$. Compared with women whose levels were not in the lowest quartile for any of these four measures, women whose levels included at least one low quartile measure showed an odds ratio of 2.0 (1.1-3.5) adjusted for maternal age and race/ethnicity. Women with two or more low quartile measures showed similar effects (odds ratio $=1.8[1.0-3.2])($ data not shown).

\section{DISCUSSION}

To our knowledge, this is the first prospective study conducted to examine potential associations between several serum nutrients related to one-carbon metabolism and CLP risk. These data did not show a difference in mid-pregnancy serum folate levels between women whose pregnancies involved CLP and those whose pregnancies did not involve a structural malformation. The lack of an association with serum folate might be expected given that women were from a population whose food supply was fortified with folic acid and that most women likely were users of prenatal supplements containing folic acid as well as some of the other measured nutrients at the time of serum sampling. Our study shows notable findings for pyridoxal phosphate, choline, and symmetric dimethylarginine.

Pyridoxal phosphate is the predominant form of $\mathrm{B}_{6}$ in human plasma (25). Similar to our observations, lower levels of this vitamin have been associated with an increased CLP risk in several populations $(19,21,22,26)$, and there is experimental evidence to support an association between clefting and $\mathrm{B}_{6}$. For example, mice fed a vitamin $\mathrm{B}_{6}$-containing diet show a reduction in corticosteroid-induced clefting (27). In addition, our analyses involving a B-vitamin-related index (pyridoxal phosphate, riboflavin, betaine, and vitamin $\mathrm{B}_{12}$ ) indicated low levels were associated with increased CLP risk. However, we also observed increased risks associated with higher levels, a finding not previously observed. Previous studies have collected specimens after delivery, often several years or more from the embryonic time of interest. The extent to which this design difference between current and previous work may contribute to differences in results is not clear. Pyridoxal phosphate has been shown to be stable for periods much longer and for freeze conditions at much higher temperatures than those associated with this study (25). However, 
our findings may be spurious given that pyridoxal phosphate is light sensitive (28) and we cannot be sure that specimen handling avoided exposure to light. Further, some of our observations with pyridoxal phosphate were consistent with an interpretation of random fluctuation.

Choline, known primarily in the diet as a component of lecithin, is key to several metabolic processes. Like folate, choline is involved in one-carbon metabolism, it is used for the synthesis of cell membrane phospholipids, and it is a precursor of the neurotransmitter, acetylcholine (29-33). The demand for choline is thought to be higher during pregnancy (33). Our observed association with choline is unlikely to be explained by differential use of prenatal vitamin supplements between case and control mothers because choline is not a typical component of multivitamin supplements. However, the increased CLP risk observed for increased levels of choline is counter to our a priori expectation. Previous work by us showed higher dietary intakes of choline to be associated with decreased risk of CLP (15) and neural tube defects (34). We have also observed higher serum choline levels to be associated with decreased risks of neural tube defects (unpublished observations). Neural tube defects and CLP are believed to share embryologic features primarily based on a shared embryologic origin of cells contributing to the neural tube and to craniofacial development. We cannot provide a meaningful explanation as to why the risk pattern would be opposite to what we might have predicted. We do know that other aspects surrounding one-carbon metabolism have been shown to differ between CLP and neural tube defects, e.g., in some studies, the association with the TT genotype of the MTHFR gene appears to be a modest risk factor for neural tube defects (35) and somewhat of a protective factor for CLP $(36,37)$.

A biologic explanation to support our findings for symmetric dimethylarginine and asymmetric dimethylarginine, that is, primarily decreased risks with increased levels, is unknown. Symmetric dimethylarginine is an indicator of renal function, asymmetric dimethylarginine inhibits nitric oxide synthase, and both are considered markers or risk factors for cardiovascular disease $(38-40)$. We are not aware of any previous studies involving these analytes relative to risks of birth defects. Elevated asymmetric dimethylarginine has been negatively implicated in other reproductive outcomes such as preeclampsia and intrauterine growth retardation (41). Therefore, the relative importance of these analytes to CLP risk will need to be replicated in future work.

Limitations of this study include, first, the collection of women's specimens on average 8 wk after closure of lip and palate. It is likely that bias due to this single point-in-time measurement would tend to result in an underestimate of measured effects. A second limitation is potential degradation of analytes based on collection and storage procedures. It has been demonstrated that folate may degrade when frozen at higher temperatures $\left(-20^{\circ} \mathrm{C}\right)$ than were used for samples in this study $\left(-80^{\circ} \mathrm{C}\right)(42)$. Such degradation would likely be nondifferential to case and control status and therefore tend to lead to underestimates of measured effects. Moreover, the average length of time between collection and frozen storage was similar between cases and controls. However, we ex- plored whether even small differences between cases and controls influenced observed effects with analytes. Analyses that incorporated length of time into models produced similar odds ratios. Other limitations included a lack of information on supplemental and dietary intake of the nutrients studied here, a relatively small sample size that reduced power in some comparisons, findings for pyridoxal phosphate, choline, and symmetric dimethylarginine that may have arisen as a result of multiple comparisons, and an inability to investigate allelic variants of genes involved in the biosynthesis of some of the studied nutrients, e.g., folate, choline, $\mathrm{B}_{6}$, and $\mathrm{B}_{12}$. Additional study of genetic variants coupled with analyte measures would be informative owing to the known or suspected function of selected one-carbon metabolism-related genes and CLP (36,37,43-46).

Evidence continues to accumulate to show that nutrients, particularly folate, influence risks of structural birth defects. Our results substantially extend observations that vitamin $B_{6}$ may be important in craniofacial development. Our observations with choline also highlight the complexity of one-carbon metabolism as it relates to embryonic development.

Acknowledgments. We thank the California Department of Public Health Maternal Child and Adolescent Health Division for providing data for these analyses.

\section{REFERENCES}

1. Shaw GM, Lammer EJ, Wasserman CR, O'Malley CD, Tolarova MM 1995 Risks of orofacial clefts in children born to women using multivitamins containing folic acid periconceptionally. Lancet 346:393-396

2. Itikala PR, Watkins ML, Mulinare J, Moore CA, Liu Y 2001 Maternal multivitamin use and orofacial clefts in offspring. Teratology 63:79-86

3. Loffredo LC, Souza JM, Freitas JA, Mossey PA 2001 Oral clefts and vitamin supplementation. Cleft Palate Craniofac J 38:76-83

4. Czeizel AE, Toth M, Rockenbauer M 1996 Population-based case control study of folic acid supplementation during pregnancy. Teratology 53:345-351

5. Czeizel AE, Hirschberg J 1997 Orofacial clefts in Hungary. Epidemiological and genetic data, primary prevention. Folia Phoniatr Logop 49:111-116

6. Werler MM, Hayes C, Louik C, Shapiro S, Mitchell AA 1999 Multivitamin supplementation and risk of birth defects. Am J Epidemiol 150:675-682

7. van Rooij IA, Ocké MC, Straatman H, Zielhuis GA, Merkus HM, SteegersTheunissen RP 2004 Periconceptional folate intake by supplement and food reduces the risk of nonsyndromic cleft lip with or without cleft palate. Prev Med 39:689-694

8. Johnson CY, Little J 2008 Folate intake, markers of folate status and oral clefts: is the evidence converging? Int J Epidemiol 37:1041-1058

9. Tolarová M 1987 Orofacial clefts in Czechoslovakia: Incidence, genetics and prevention of cleft lip and palate over a 19-year period. Scand J Plast Reconstr Surg Hand Surg 21:19-25

10. Badovinac RL, Werler MM, Williams PL, Kelsey KT, Hayes C 2007 Folic acidcontaining supplement consumption during pregnancy and risk for oral clefts: a meta-analysis. Birth Def Res A Clin Mol Teratol 79:8-15

11. Wilcox AJ, Lie RT, Solvoll K, Taylor J, McConnaughey DR, Abyholm F, Vindenes H, Vollset SE, Drevon CA 2007 Folic acid supplements and risk of facial clefts: national population based case-control study. BMJ 334:464

12. Yazdy MM, Honein MA, Xing J 2007 Reduction in orofacial clefts following folic acid fortification of the US grain supply. Birth Def Res A Clin Mol Teratol 79:16-23

13. Hernández-Díaz S, Werler MM, Walker AM, Mitchell AA 2000 Folic acid antagonists during pregnancy and the risk of birth defects. N Engl J Med 343:1608-1614

14. Natsume N, Nagatsu Y, Kawai T 1998 Direct effect of vitamins at the time of palatal fusion. Plast Reconstr Surg 102:2512-2513

15. Shaw GM, Carmichael SL, Laurent C, Rasmussen SA 2006 Maternal nutrient intakes and risk of orofacial clefts. Epidemiology 17:285-291

16. Krapels IP, van Rooij IA, Ocké MC, West CE, van der Horst CM, SteegersTheunissen RP 2004 Maternal nutritional status and the risk for orofacial cleft offspring in humans. J Nutr 134:3106-3113

17. Krapels IP, van Rooij IA, Ocké MC, van Cleef BA, Kuijpers-Jagtman AM, Steegers-Theunissen RP 2004 Maternal dietary B vitamin intake, other than folate, and the association with orofacial cleft in the offspring. Eur J Nutr 43:7-14

18. Bille C, Olsen J, Vach W, Knudsen VK, Olsen SF, Rasmussen K, Murray JC, Andersen AM, Christensen K 2007 Oral clefts and life style factors - A case-cohort study based on prospective danish data. Eur J Epidemiol 22:173-181 
19. Wong WY, Eskes TK, Kuijpers-Jagtman AM, Spauwen PH, Steegers EA, Thomas CM, Hamel BC, Blom HJ, Steegers-Theunissen RP 1999 Nonsyndromic orofacial clefts: association with maternal hyperhomocysteinemia. Teratology 60:253-257

20. Krapels IP, Rooij IA, Wever RA, Zielhuis GA, Spauwen PH, Brussel W, SteegersTheunissen RP 2004 Myo-inositol, glucose, and zinc status as risk factors for non-syndromic cleft lip with or without cleft palate in offspring: a case-control study. BJOG 111:661-668

21. van Rooij IA, Swinkels DW, Blom HJ, Merkus HM, Steegers-Theunissen RP 2003 Vitamin and homcysteine status of mothers and infants and the risk of nonsyndromic orofacial clefts. Am J Obstet Gynecol 189:1155-1160

22. Munger RG, Sauberlich HE, Corcoran C, Nepomuceno B, Daack-Hirsch S, Solon FS 2004 Maternal vitamin B-6 and folate status and risk of oral cleft birth defects in the Philippines. Birth Def Res A Clin Mol Teratol 70:464-471

23. Croen LA, Shaw GM, Jensvold NJ, Harris JA 1991 Birth defects monitoring in California: A resource for epidemiological research. Paediatr Perinat Epidemiol 5:423-427

24. Ueland PM, Midttun O, Windelberg A, Svardal A, Skålevik R, Hustad S 2007 Quantitative profiling of folate and one-carbon metabolism in large-scale epidemiological studies by mass spectrometry. Clin Chem Lab Med 45:1737-1745

25. Tamura T, Munger RG, Nepomuceno B, Corcoran C, Cembrano J, Solon F 2007 Maternal plasma pyridoxal-5'-phosphate concentrations and risk of isolated oral clefts in the Philippines. Birth Def Res A Clin Mol Teratol 79:276-280

26. Yoneda T, Pratt RM 1982 Vitamin B6 reduces cortisone-induced cleft palate in the mouse. Teratology 26:255-258

27. Sauberlich HE, Dowdy RP, Skala JH 1973 Laboratory tests for the assessment of nutritional status. CRC Crit Rev Clin Lab Sci 4:215-340

28. Vilanova B, Adrover M, Muñoz F, Donoso J 2004 Photo-induced processes in vitamin B6 compounds. Chem Biodivers 1:1073-1090

29. Zeisel SH 2000 Choline: needed for normal development of memory. J Am Coll Nutr 19:528S-531S

30. Zeisel SH, Blusztajn JK 1994 Choline and human nutrition. Annu Rev Nutr $14: 269-296$

31. Shronts EP 1997 Essential nature of choline with implications for total parenteral nutrition. J Am Diet Assoc 97:639-646:649

32. Zeisel SH 1997 Choline: essential for brain development and function. Adv Pediatr 44:263-295

33. Fisher MC, Zeisel SH, Mar MH, Sadler TW 2001 Inhibitors of choline uptake and metabolism cause developmental abnormalities in neuralating mouse embryos. Teratology 64:114-122

34. Shaw GM, Carmichael SL, Yang W, Selvin S, Schaffer DM 2004 Periconceptional dietary intake of choline and betaine and neural tube defects in offspring. Am J Epidemiol 160:102-109
35. Botto LD, Yang Q 2000 5,10-Methylenetetrahydrofolate reductase gene variants and congenital anomalies: a HuGE review. Am J Epidemiol 151:862-877

36. Shaw GM, Rozen R, Finnell RH, Todoroff K, Lammer EJ 1998 Infant C677T mutation in MTHFR, maternal periconceptional vitamin use, and cleft lip. Am J Med Genet 80:196-198

37. Chevrier C, Perret C, Bahuau M, Zhu H, Nelva A, Herman C, Francannet C, Robert-Gnansia E, Finnell RH, Cordier S 2007 Fetal and maternal MTHFR C677T genotype, maternal folate intake and the risk of nonsyndromic oral clefts. Am J Med Genet A 143:248-257

38. Kielstein JT, Salpeter SR, Bode-Boeger SM, Cooke JP, Fliser D 2006 Symmetric dimethylarginine (SDMA) as endogenous marker of renal function - a metaanalysis. Nephrol Dial Transplant 21:2446-2451

39. Bode-Böger SM, Boger RH, Kienke S, Junker W, Frölich JC 1996 Elevated L-arginine/dimethylarginine ratio contributes to enhanced systemic NO production by dietary L-arginine in hypercholesterolemic rabbits. Biochem Biophys Res Commun 219:598-603

40. Cooke JP 2000 Does ADMA cause endothelial dysfunction? Arterioscler Thromb Vasc Biol 20:2032-2037

41. Savvidou MD, Hingorani AD, Tsikas D, Frölich JC, Vallance P, Nicolaides KH 2003 Endothelial dysfunction and raised plasma concentrations of asymmetric dimethylarginine in pregnant women who subsequently develop pre-eclampsia. Lancet 361:1511-1517

42. Lawrence JM, Umekubo MA, Chiu V, Petitti DB 2000 Split sample analysis of serum folate levels after 18 days in frozen storage. Clin Lab 46:483-486

43. van Rooij IA, Vermeij-Keers C, Kluitmans LA, Ocké MC, Zielhuis GA, GoorhuisBrouwer SM, van der Biezen JJ, Kuijpers-Jagtman AM, Steegers-Theunissen RP 2003 Does the interaction between maternal folate and the methylenetetrahydrofolate reductase polymorphisms affect the risk of cleft lip with or without cleft palate? Am J Epidemiol 157:583-591

44. Rubini M, Brusati R, Garattini G, Magnani C, Liviero F, Bianchi F, Tarantino E, Massei A, Pollastri S, Carturan S, Amadon A, Bertagnin E, Cavallaro A, Fabiano A, Franchella A, Calzolari E 2005 Cystathionine beta-synthase c. 844ins68 gene variant and non-syndromic cleft lip and palate. Am J Med Genet A 136A:368-372

45. Mills JL, Molloy AM, Parle-McDermott A, Troendle JF, Brody LC, Conley MR, Cox C, Pangilinan F, Orr DJ, Earley M, McKiernan E, Lynn EC, Doyle A, Scott JM, Kirke PN 2008 Folate-related gene polymorphisms as risk factors for cleft lip and cleft palate. Birth Def Res A Clin Mol Teratol 82:636-643

46. Boyles AL, Wilcox AJ, Taylor JA, Meyer K, Fredriksen A, Ueland PM, Drevon CA, Vollset SE, Lie RT 2008 Folate and one-carbon metabolism gene polymorphisms and their associations with oral facial clefts. Am J Med Genet A 146A:440-449 